\title{
An Assessment of "Knowledge" of Beneficiaries and Non-Beneficiaries regarding Diversified Agriculture Support Project (DASP) in District Allahabad (Uttar Pradesh), India
}

\author{
H. A. Malik ${ }^{1 *}$, Nusrat $\mathrm{Jan}^{2}$ and Sabiha Ashraf ${ }^{3}$ \\ ${ }^{I}$ Directorate of Extension, SKUAST-Kashmir, India \\ ${ }^{2}$ A. E. A, Department of Agriculture, GoJK, Bandipora, Kashmir, India \\ ${ }^{3}$ College of Temperate Sericulture, SKUAST-Kashmir, India \\ *Corresponding author
}

\section{Keywords}

Knowledge, Impact,

Technological

interventions,

World Bank, farm

yield

\section{Article Info}

Accepted:

28 February 2020

Available Online:

10 March 2020

\section{A B S T R A C T}

A study was conducted in District Allahabad, Uttar Pradesh State of India to assess the knowledge of beneficiaries and non-beneficiaries towards different scientific interventions and their potential prospects being offered under World Bank supported flagship programme viz Diversified Agriculture Support Project (DASP). For this purpose, a series of relevant questions / statements with respect of Agriculture (Crop Husbandry), Horticulture, Animal Husbandry, Fisheries and Sericulture were administered on beneficiaries and non-beneficiaries. The major findings of the study revealed that majority of beneficiaries (50.66 per cent) had high level of knowledge and percentage of beneficiaries with medium of knowledge was estimated at 40.00 while 9.33 per cent of the beneficiaries had low level of knowledge. In comparison, majority of Non-beneficiaries (88.66 per cent) had low level of knowledge followed by 9.33 per cent with medium level of knowledge and only 2.00 per cent of non-beneficiaries had high level of knowledge. The data reflected that beneficiaries had comparatively high level of knowledge than nonbeneficiaries regarding agriculture technologies being provided to them through DASP. The knowledge gained through scientific interventions, trainings, demonstrations and other important extension activities was highly instrumental for increasing the farm yields and net returns of beneficiaries under DASP than Non-beneficiaries who were seen lagging behind on almost all attributes \& parameters designed for the purpose.

\section{Introduction}

A broader initiative in the form of Diversified Agriculture Support Project (DASP) was introduced by the Government of India for technology development and dissemination with respect to agriculture and allied sectors in two States - Uttar Pradesh and Uttaranchal with financial support from the World Bank with the objective to accelerate the growth of UP's diversified agriculture in relation to agro-ecological potential and well designed market demand system. At the time of initiation of this project, contribution of Uttar 
Pradesh was 41.8 million tons in the national food grain production of 194.1 million tons. By the end of year 2015-16, the contribution of Uttar Pradesh was targeted at 44.01 million tons in the national food grain production of 252.22 million tonnes (Anonymous-2016) ${ }^{1}$. Social capital has positive impacts on agricultural production and income of the people (Yokoyama,-S; Sakurai,-T, (2003) ${ }^{5}$. Therefore, cluster approach and development of small organization was one of the major focuses under DASP.

Since these organizations undertake a great variety of strategies to increase their incomes through improved farm management and diversified income sources (Guyau, $-L 2004)^{2}$. Therefore, the financial support and quantum of assistance provided under DASP, technological backstopping, critical inputs supplied, training and demonstrations conducted under the programme offered a tremendous scope to assess and evaluate the knowledge gained and skill developed on practical aspects of the given potential technologies and the benefits of such interventions thereof in terms of increased quality production, productivity, efficient marketing facilities, better returns by the beneficiaries compared to Non-beneficiaries who were believed to still follow traditional system of agriculture. Under the above backdrop, the present study was carried out with five objectives wherein one of the important objectives was, "To assess the level of knowledge of beneficiaries and nonbeneficiaries towards agricultural intervention/innovation"

\section{Materials and Methods}

Uttar Pradesh consists of 32 districts and the project activities were implemented by the Government in the selected blocks of all districts in the State which had the potential to serve as growth centers and where infrastructure and institutions are developed and scope for private sector investments was high. The farming communities were mobilized for problem /issue identification, joint problem solving and efficient technology dissemination. Allahabad district was selected purposively for the study. It is pertinent to mention here that in selected district, 5 blocks were brought under DASP programme by the Government and two villages from each block were randomly selected for the study.

The respondents were sixty in each block covering five blocks with 10 villages; total size of sample consists of 300 respondents' with150 beneficiaries and 150 nonbeneficiaries. Stratified random sampling procedure was adopted for the study. Keeping in view the purpose and objectives of the study, information and opinions were obtained firstly on pilot basis followed through personal interview with the help of well-designed prestructured schedule. The data collected from beneficiaries and non-beneficiaries were then tabulate, analyzed in light of pre- determined objectives for the present study.

Further, in order to determine the level of knowledge of beneficiaries and nonbeneficiaries with respect to Agriculture (Crop Husbandry), Horticulture, Animal Husbandry, Sericulture and Fisheries a series of relevant questions/ statements were administered on beneficiaries and non-beneficiaries. Each item and response were given a particular score, the score level were first categorized into 'No knowledge' (NK), 'Partial knowledge' (PK) and 'Full knowledge' (FK). A score of zero was given for 'No knowledge', 1 for 'Partial knowledge' and 2 for 'Full knowledge'. Thus the total score for each item and each respondent were summarized and tabulated. Suitable Statistical measures were adopted to determine the comparative analysis in respect of knowledge of beneficiaries and nonbeneficiaries. 


\section{Results and Discussion}

\section{Knowledge level of respondents}

In order to determine the level of knowledge of beneficiaries and non-beneficiaries with respect to Agriculture (Crop Husbandry), Horticulture, Animal Husbandry, Sericulture and Fisheries a series of most relevant and important questions were framed. The number of questions administered for the purpose with respect to Agriculture (Crop Husbandry) were 21, for Horticulture the number of questions were 7, 5 questions were designed for Animal Husbandry, 4 for Fisheries and 3 questions were formulated for Sericulture, thus a total number of forty (40) questions were enlisted regarding the level of knowledge of beneficiaries and non-beneficiaries towards scientific interventions regarding Agriculture \& Allied activities. The statements thus designed for the purpose is highlighted under Table-1

Each item (statement) and response were given a particular score, the score levels were first categorized into 'No knowledge' (NK), 'Partial knowledge' (PK) and 'Full knowledge' (FK). A score of 0 (zero) was given for 'No knowledge', 1 (one) for 'Partial knowledge' and 2 (two) for 'Full knowledge'. Thus the total score for each item and each respondent were summarized and tabulated.

Analysis of the data revealed that in case of beneficiaries the lowest score was estimated at 20 while the highest score was recorded as 40 with an average (mean) score and standard deviation of 29.40 and 5.70 respectively. Similarly, in case of non-beneficiaries the lowest score was estimated at 10 while the highest score was recorded as 30 with an average (mean) score and standard deviation of 14.36 and 4.10 respectively. Thus a significant \& prominent difference could be felt in terms of knowledge of scientific interventions between beneficiaries and nonbeneficiaries. The beneficiaries brought under the ambit of DASP were at par in respect of scientific knowledge than that of nonbeneficiaries. The same is summarized under Table-2

\section{Comparison of Knowledge of the respondents}

In order to find out whether there was a significant difference between the beneficiaries and non-beneficiaries with respect to their level of knowledge regarding various technologies; the following Hypothesis was formulated for the purpose:

Null Hypothesis (Ho): There was no significant difference between beneficiaries and non-beneficiaries in respect of their level of knowledge regarding various agriculture technologies.

Research Hypothesis $\left(H_{1}\right)$ : There was a significant difference between beneficiaries and non-beneficiaries in respect of their level of knowledge regarding various agriculture technologies.

After due consultation with statistician and based on the nature of data, the Chi- square test was adopted for testing these hypothesis.

Chi -Square test $\left(\mathrm{X}^{2}\right.$-test $)$

$$
X^{2}=\frac{(O-E)^{2}}{E}
$$

Where;

$\mathrm{O}$ is the "Observed Frequency" in each category

$\mathrm{E}$ is the "Expected Frequency" in the corresponding category 
Table.1 Knowledge statements regarding Agriculture \& Allied sectors

\begin{tabular}{|c|c|c|c|c|}
\hline S.No & Statement & N.K* & P.K* & F.K* \\
\hline 1. & Knowledge regarding Agriculture (Crop Husbandry) & & & \\
\hline 1.1 & What are high yielding varieties & & & \\
\hline 1.2 & Do you use high yielding varieties & & & \\
\hline 1.3 & The recommended dose of $\mathrm{N}: \mathrm{P}: \mathrm{K}$ for Wheat is $120: 60: 40$ & & & \\
\hline 1.4 & The recommended dose of N:P:K for Rice is $120: 60: 60$ & & & \\
\hline 1.5 & What is organic farming & & & \\
\hline 1.6 & What is Integrated Nutrient Management (INM)? & & & \\
\hline 1.7 & Do you use bio-fertilizers & & & \\
\hline 1.8 & Can you name some of the bio-fertilizers & & & \\
\hline 1.9 & Why Soil testing is necessary. & & & \\
\hline 1.10 & What necessary measures should be taken before Soil testing? & & & \\
\hline 1.11 & Do you have Soil Health Card. & & & \\
\hline 1.12 & Do you follow the recommendations as per the status of the Soil Health Card. & & & \\
\hline 1.13 & What is the symbol of a quality seed? & & & \\
\hline 1.14 & Do you carry out seed treatment? & & & \\
\hline 1.15 & What is Integrated Pest Management (IPM)? & & & \\
\hline 1.16 & Can you name some of the common diseases of your crops & & & \\
\hline 1.17 & What is zero-tillage & & & \\
\hline 1.18 & What are the advantages of zero -tillage & & & \\
\hline 1.19 & Why crop rotation is necessary & & & \\
\hline 1.20 & What is vermi-compost & & & \\
\hline 1.21 & How much time will it take to prepare vermin-composite. & & & \\
\hline 2. & Knowledge regarding Horticulture & & & \\
\hline 2.1 & What is Diversification of Agriculture & & & \\
\hline 2.2 & How can you make your agriculture more remunerative \& demand driven & & & \\
\hline 2.3 & Can you please name some of the important insects/pests of vegetables? & & & \\
\hline 2.4 & Have you ever been trained to grow vegetable crops under "protected cultivation". & & & \\
\hline 2.5 & Have you brought more land under fruits/vegetables after joining DASP? & & & \\
\hline 2.6 & What is intercropping? & & & \\
\hline 2.7 & Have you ever participated in any V N T programme organized by DASP? & & & \\
\hline 3. & Knowledge regarding Animal Husbandry & & & \\
\hline 3.1 & What is artificial insemination & & & \\
\hline 3.2 & A.I has got less chance for conceiving animal. & & & \\
\hline 3.3 & $\begin{array}{l}\text { Have you ever received any guidance/input from paravet services operating in your } \\
\text { village? }\end{array}$ & & & \\
\hline 3.4 & Can you specify some crossbreeds animals & & & \\
\hline 3.5 & The average milk yield of local cow (lit/day/animal) and crossbreed cow is same & & & \\
\hline 4. & Knowledge regarding Fisheries & & & \\
\hline 4.1 & Do you know fish farm & & & \\
\hline 4.2 & Are you doing fish farming on a group basis & & & \\
\hline 4.3 & Have you taken the land on lease? & & & \\
\hline 4.4 & Is good quality seed available at Govt fisheries centre? & & & \\
\hline 5. & Knowledge regarding Sericulture & & & \\
\hline 5.1 & Do you know about Sericulture? & & & \\
\hline 5.2 & Do you rear silk-worm & & & \\
\hline 5.3 & $\begin{array}{l}\text { Do you get technical advice/input about scientific rearing of silk-worm from the } \\
\text { concerned Department/University / KVK? }\end{array}$ & & & \\
\hline
\end{tabular}

N.K* $=$ No knowledge $($ score $=0)$

P.K* = Partial knowledge (score $=1)$ and

F.K* $\mathbf{K}^{*}$ Full knowledge $($ score $=2)$ 
Table.2 Statistical measures with respect of knowledge of the respondents

\begin{tabular}{|c|c|c|}
\hline Statistical measure & Beneficiaries & Non-Beneficiaries \\
\hline Mean (average score) & 29.40 & 14.36 \\
\hline Standard deviation & 5.70 & 4.10 \\
\hline Range (score) & 20 to 40 & 10 to 30 \\
\hline
\end{tabular}

Table.3 Classification of the Knowledge score of the respondents

$(\mathrm{N}=300)$

\begin{tabular}{|c|c|c|c|}
\hline S.No & Knowledge level & Beneficiaries & Non-beneficiaries \\
\hline 1 & Low (10-20) & $14(9.33)$ & $133(88.67)$ \\
\hline 2 & Medium (20-30) & $60(40.00)$ & $14(9.33)$ \\
\hline 3 & High (above30) & $76(50.67)$ & $03(2.00)$ \\
\hline
\end{tabular}

Calculated $. X^{2}=192.38$

Tabulated. $X^{2}$ at 2 degree of freedom and 5\% probability level=5.991

Note: Figures in parenthesis are the percentage (\%).

The knowledge score for each statement and response for beneficiaries and nonbeneficiaries were calculated, summarized and tabulated. The score levels were then classified into three categories i.e Low, Medium and High. For low knowledge level, the score ranges from 10 to 20 , for medium it was 20 to 30 and above 30 score was classified into high level score. It was observed that in case of beneficiaries 50.67 per cent of the respondents were observed to have high level of knowledge followed by 40.00 per cent with medium level of knowledge and 9.33 per cent of the respondents had low level of knowledge. However, in case of non-beneficiaries the results were found very much different with 88.67 per cent of the respondents having low level of knowledge followed by 9.33 per cent with medium level of knowledge and only 2.00 per cent of respondents were found to have high level of knowledge. The results were in conformity with the study conducted by Vinod-Prakash $(2007)^{4}$ who found that most important variables including education, size of land holding (ha), occupation, farm power, annual income and extension contact were found highly significant and positively correlated with extent of knowledge of the respondents. Further, Subhash; Mehta et al., $(2006)^{3}$ found that all the socioeconomic characteristics except age had positive and significant association with farmers' knowledge level about the recommended technologies. The Knowledge score thus obtained is highlighted under Table-3

Calculated $X^{2}$ was found greater than tabulated $X^{2}$ at 2 degree of freedom and 5\% probability level, hence Null hypothesis (Ho) was rejected and Research Hypothesis $\left(\mathrm{H}_{1}\right)$ got accepted. Therefore, it was concluded that there was a significant difference between beneficiaries and non-beneficiaries with respect to their level of knowledge. The beneficiaries had comparatively high level of knowledge than non-beneficiaries regarding agriculture technology being provided through DASP.

It was concluded that besides various factors including transfer of the demand driven / 
farmer-oriented / need based technologies and their adoption coupled with effective extension services and timely advisories that resulted in higher production / productivity and enhanced farm income to the beneficiaries compared to non-beneficiaries; one of the very important factors instrumental in this regard was- "Knowledge and its adoption" on scientific interventions related to agriculture \& allied activities that were provided to the beneficiaries through need based trainings on thematic areas, skill orientations programmes, demonstrations, learning by doing and other innovative extension approaches.

\section{References}

Anonymous (2016) Agricultural Statistics at a Glance 2016,GoI, Ministry of Agriculture \& Farmers Welfare, Directorate of Economics and Statistics wing.

Guyau,-L (2004); Economic organization: an asset for world farmers, Paris, France: Assemblee Permanente des Chambresd' Agriculture, Chambers-d'-
Agriculture. (934): 9-30

Subhash-Chander; Mehta,-S-K et. Al (2006), Relationships of farmers' socioeconomic traits with their knowledge level about pearl millet production technology, Hisar, India: Agri Bio Research Publishers., Annals-of-AgriBio-Research.; 11(1): 89-92

Vinod-Prakash, (2007), Impact of knowledge of potato growers regarding potato production technology, Muzaffarnagar, India: Hind Agri-Horticultural Society, International- Journal - of - Plant Sciences -Muzaffarnagar.;2(1):146150

Yokoyama,-S; Sakurai,-T, (2003), Potential of social capital for community development. Report of the APO, Tokyo, Japan: Asian Productivity Organization (APO), Potential-ofsocial-capital-for-communitydevelopment-Report-of-the-APOsurvey-and-symposium-onredesigning-integrated-communitydevelopment 250-251.

\section{How to cite this article:}

Malik, H. A., Nusrat Jan and Sabiha Ashraf 2020. An Assessment of "Knowledge" of Beneficiaries and Non-Beneficiaries regarding Diversified Agriculture Support Project (DASP) in District Allahabad (Uttar Pradesh), India. Int.J.Curr.Microbiol.App.Sci. 9(03): 3130-3135. doi: https://doi.org/10.20546/ijcmas.2020.903.358 